\title{
Research on heavy metal pollution remediation technology in farmland soil
}

\author{
Binli Shi $^{1}$, Xiaohui Zhang ${ }^{1}$, and Aiping Gou ${ }^{1 *}$ \\ ${ }^{1}$ College of Ecological Technology and Engineering, Shanghai Institute of Technology, Shanghai, 201418, China
}

\begin{abstract}
Soil is the foundation of agricultural sustainable development. After nearly 40 years of rapid economic development and highly intensive agricultural production, our country's farmland soil is facing severe soil heavy metal pollution. The situation of heavy metal pollution in farmland soil in China is not optimistic and poses a threat to the safe production of agricultural products and food safety. Therefore, the treatment and restoration of soil heavy metal pollution has received extensive attention. According to the actual situation of soil pollution in our country, the prevention, control and remediation of soil heavy metal pollution has become a major national demand. This article discusses the current status of soil heavy metal pollution control in our country and the main remediation technologies. Aiming at the characteristics and shortcomings of various remediation technologies, it proposes the improvement and development direction of heavy metal contaminated soil remediation technology to provide reference for soil remediation technology research.
\end{abstract}

\section{Introduction}

Soil heavy metal pollution means that the content of heavy metals in the soil caused by industrial and agricultural production activities or human activities is higher than the background level, which leads to a potential decline in soil quality and affects the ecological environment [1]. About $20 \%$ of the agricultural land in our country is polluted by heavy metals, and the annual loss of grain is more than 10 million tons [2]. With the continuous development of industry and agriculture in our country, the pollution of heavy metals in the soil has become increasingly serious. The heavy metals that cause soil environment pollution mainly include mercury $(\mathrm{Hg})$, cadmium $(\mathrm{Cd})$, lead $(\mathrm{Pb})$, metalloid arsenic (As) and other elements with significant biological toxicity. They also include zinc $(\mathrm{Zn})$, copper $(\mathrm{Cu})$, cobalt $(\mathrm{Co})$ and other common elements with some toxicity. Heavy metals cannot be decomposed by microorganisms in the soil, so they will continue to accumulate in the soil, affecting the properties of the soil, and can even be converted into more toxic alkyl compounds. For farmland, heavy metal pollution will reduce soil fertility and crop yields, and cause heavy metal content in crops to exceed the standard. Heavy metals will pollute surface runoff and groundwater with rainfall, destroy the water environment, and may directly poison plants or harm the human body as well as other animal health through the food chain and cause cancer and other diseases(table 1). The heavy metals in the soil have low mobility and strong stability, and the pollution effect of heavy metals is also long-term and irreversible [3]. Therefore, it has attracted great attention of comprehensively remediating soil heavy metal pollution. At present, the remediation technologies for heavy metal pollution in the soil include physical remediation, chemical remediation, biological remediation, agricultural ecological remediation and joint remediation technologies [4].

Table 1. Human health effects of soil chemical pollution

\begin{tabular}{|c|c|}
\hline Chemicals & Human health effects \\
\hline Chrome & Skin disease \\
\hline Benzene & $\begin{array}{c}\text { Harmful effects on blood, } \\
\text { leukemia }\end{array}$ \\
\hline Dibromochloropropane & $\begin{array}{c}\text { Decreased sperm count, } \\
\text { infertility }\end{array}$ \\
\hline Lead & $\begin{array}{c}\text { Infertility, miscarriage, } \\
\text { stillbirth, insanity }\end{array}$ \\
\hline Chloroethylene & Angiosarcoma, liver cancer \\
\hline Asbestos & Lung cancer \\
\hline $\begin{array}{c}\text { Polychlorinated } \\
\text { biphenyl }\end{array}$ & Chloracne \\
\hline
\end{tabular}

\section{Current status of heavy metal pollution in farmland soil}

As a large industrial country, our country faces a particularly severe problem of heavy metal pollution in the soil. Our country's soils with varying degrees of heavy metal pollution have been close to 20 million hectares, among which the ecological environment, food safety and regional human health risks caused by lead $(\mathrm{Pb})$ and cadmium $(\mathrm{Cd})$ pollution are the most serious

\footnotetext{
* Corresponding author: shyyjsbls@163.com
} 
[5]. The annual reduction in grain production due to heavy metal pollution is as much as 12 million tons, and the total economic loss is 20 billion yuan [6]. The survey results of the national 300,000 hectares basic farmland preservation area by the Key Laboratory of Agricultural Products Pollution Prevention and Control showed that the rate of excess heavy metals was $12.1 \%$, and that of grain heavy metals was more than $10 \%$ [7]. Among the contaminated soils, the heavily polluted area accounts for $8.4 \%$, the moderately polluted area accounts for $9.7 \%$, and the lightly polluted area accounts for $46.7 \%$. There are many sources of heavy metals in farmland soil. First, the parent material itself contains heavy metals, and the types and contents of heavy metals in the soil formed by different parent materials are quite different [8]. In the soil/groundwater system, these heavy metals exist in the form of carbonates, sulfides, oxides or salts [9]. Secondly, with the rapid economic development in recent years, the intensification of industrial and urban pollution, and the increase in the use of agrochemicals, the heavy metal pollution of farmland soil has become more severe. In several major cities in China, almost all the measured heavy metal concentrations in suburban farmland soil and even outer suburban farmland soil are higher than the natural background value [10].

A recent survey of various heavy metal pollution in black soil in northeastern China showed that the heavy metal cadmium pollution is more common. It can be seen that the content of cadmium in black soil samples ranges from 0.013 to $2.31 \mathrm{mg} / \mathrm{kg}$, the pollution index Pi is between 0.06 and 4.87. Among the sample points surveyed, $42.5 \%$ of the samples were contaminated by cadmium. Among the contaminated samples, light pollution accounted for $33.3 \%$, moderate and severe pollution accounted for $66.7 \%$ (table 2 ). In terms of the location of black soil pollution, the samples of cadmium element pollution are mainly concentrated in the urban area and the urban-rural junction(table 3 ). The pollution of cadmium is also different between various black soil agricultural land. Cadmium pollution in soybean fields and corn fields is relatively light(table 4).

Table 2. Heavy metal pollution trend of soil samples $(\mathrm{n}=105)$

\begin{tabular}{|c|c|c|c|c|c|c|}
\hline Element & $\begin{array}{c}\text { Detection range/ } \\
(\mathrm{mg} / \mathrm{kg})\end{array}$ & $\begin{array}{c}\text { Pollution index } \\
\text { level }\end{array}$ & $\begin{array}{c}\text { No pollution } \\
\text { samples } \mathrm{Pi} \leq 1\end{array}$ & $\begin{array}{c}\text { Light pollution } \\
\text { samples } 1<\mathrm{Pi} \leq 2\end{array}$ & $\begin{array}{c}\text { Moderate pollution } \\
\text { samples 2 }<\mathrm{Pi} \leq 3\end{array}$ & $\begin{array}{c}\text { Heavy pollution } \\
\text { samples } \mathrm{Pi}>3\end{array}$ \\
\hline Lead & $10.52 \sim 57.48$ & $0.30 \sim 1.08$ & 104 & 1 & 0 & 0 \\
\hline Cadmium & $0.013 \sim 2.31$ & $0.06 \sim 4.87$ & 60 & 15 & 28 & 2 \\
\hline Copper & $9.95 \sim 46.18$ & $0.28 \sim 1.17$ & 104 & 1 & 0 & 0 \\
\hline Zinc & $42.13 \sim 227.10$ & $0.42 \sim 1.83$ & 82 & 23 & 0 & 0 \\
\hline
\end{tabular}

Table 3. Cadmium pollution trends in different spaces

\begin{tabular}{|c|c|c|c|c|c|}
\hline Spot type & $\begin{array}{c}\text { Total } \\
\text { samples }\end{array}$ & $\begin{array}{c}\text { No pollution samples } \\
\mathrm{Pi} \leq 1\end{array}$ & $\begin{array}{c}\text { Light pollution } \\
\text { samples } 1<\mathrm{Pi} \leq 2\end{array}$ & $\begin{array}{c}\text { Moderate pollution } \\
\text { samples 2 }<\mathrm{Pi} \leq 3\end{array}$ & $\begin{array}{c}\text { Heavy pollution } \\
\text { samples } \mathrm{Pi}>3\end{array}$ \\
\hline Farm area & 35 & 29 & 5 & 1 & 0 \\
\hline Urban area & 31 & 18 & 5 & 7 & 1 \\
\hline Urban-rural junction & 39 & 13 & 5 & 20 & 1 \\
\hline
\end{tabular}

Table 4. Pollution trend of soil cadmium in different land use types

\begin{tabular}{|c|c|c|c|c|c|}
\hline Farmland type & $\begin{array}{c}\text { Total } \\
\text { samples }\end{array}$ & $\begin{array}{c}\text { No pollution } \\
\text { samples } \mathrm{P} i \leq 1\end{array}$ & $\begin{array}{l}\text { Light pollution } \\
\text { samples } 1<\mathrm{Pi} \leq 2\end{array}$ & $\begin{array}{l}\text { Moderate pollution } \\
\text { samples } 2<\mathrm{Pi} \leq 3\end{array}$ & $\begin{array}{l}\text { Heavy pollution } \\
\text { samples } \mathrm{Pi}>3\end{array}$ \\
\hline Cabbage field & 20 & 6 & 4 & 10 & 0 \\
\hline Soybean field & 25 & 14 & 5 & 6 & 0 \\
\hline Cornfield & 30 & 25 & 3 & 1 & 1 \\
\hline Other types & 30 & 15 & 3 & 11 & 1 \\
\hline
\end{tabular}

\section{Sources of heavy metal pollution in farmland soil}

The difference in the content of heavy metals in the soil is often dominated by the human factors, and the sources are mainly industrial sources, agricultural sources and living sources [11]. Industrial sources mainly refer to the waste water and residue discharged from industrial production processes such as mining and smelting, electroplating, mechanical processing, chemical industry, coal-fired power generation, leather manufacturing, etc., which directly or indirectly permeate the soil, resulting in excessive heavy metal content in the soil. Agricultural sources mainly refer to the use of heavy metalcontaining sewage to irrigate crops in agricultural production, or the use of heavy metal-containing fertilizers, pesticides, and greenhouse films, which lead to the excess accumulation of heavy metals in the soil. Living sources mainly refer to the improper disposal of 
discarded batteries, thermometers, modulator tube, and sphygmomanometers, resulting in excessive heavy metal content in water and soil.

\section{Soil heavy metal pollution remediation technology}

The potential impact of heavy metals on farmland soil environment and human health has been recognized by the public, so it is very important to manage polluted soil and achieve sustainable development. For farmland soil pollution remediation technology, the general principles are environmentally friendly, sustainability and high efficiency [12-13].

\subsection{Physical remediation technology}

Physical remediation refers to the remediation of heavy metal pollution in the soil through physical methods, including mixing of soil method, soil replacement method, topsoil removal method, deep plowing and soil turning, thermal recovery method and electrochemical repair method. The mixing of soil method refers to mixing soil contaminated by heavy metals with nonpolluted soil uniformly to reduce the concentration of heavy metals in the soil below a hazardous concentration. The method of removing the topsoil refers to the use of engineering measures to remove the contaminated surface soil based on the characteristics of the topsoil contaminated by heavy metals, and to tillage activates the subsoil. Methods of mixing of soil, soil replacement, topsoil removal and deep plowing consume manpower, material and financial resources because of the heavy workload and are only suitable for the treatment of contaminated soil with serious pollution and small scope.

The thermal recovery method is mainly aimed at soil contaminated by heavy metals (such as mercury) with low melting points or strong volatility. This technology uses high-frequency voltage to act on the contaminated soil, which causes the soil temperature to rise and make heavy metals volatilize. Then recycled and reuse to achieve the purpose of soil restoration. However, this method has a narrow scope of application, and is only suitable for removing low-melting, volatile heavy metals.

Electrochemical remediation refers to inserting electrodes into the soil contaminated by heavy metals and passing a direct current. Under the action of an electric field, heavy metal ions undergo processes such as electromigration, electroosmosis and electrophoresis, and are concentrated near the electrodes. $\mathrm{Xu}$ Lei, et al. found that when DC voltage with a voltage gradient of 1 $\mathrm{V} / \mathrm{cm}$ and $3 \mathrm{~V} / \mathrm{cm}$ is applied to both ends of the electrode, the maximum removal rate of $1 \mathrm{~V} / \mathrm{cm}$ is $9.5 \%$, and that of $3 \mathrm{~V} / \mathrm{cm}$ is $14.7 \%$. The greater the electric field strength, the higher the removal rate. The electrothermal method is suitable for the treatment of specific volatile heavy metal pollution in the soil. However, this method is easy to cause secondary pollution and damage soil fertility, so it is not recommended to use on a large scale.

\subsection{Chemical remediation technology}

Chemical remediation technology refers to the use of chemical means, such as redox, precipitation polymerization, complex adsorption and other reactions to change the migration state and biological activity of heavy metals in the soil, and reduce the absorption of heavy metals by plants. Mainly include chemical improvement repair method, chemical leaching repair method, chemical reduction method.

The chemical improvement method refers to adding low-toxic or non-toxic chemical substances to the soil to change the physical and chemical properties of the soil through chemical reactions and reduce the content of transportable heavy metals in the soil. At present, the commonly used chemical modifiers mainly include phosphate, lime, zeolite, red mud, plant ash, calcium magnesium phosphate, biological compost, peat, livestock and poultry manure, soda ash, oxalic acid, etc. [14].

The chemical leaching remediation method refers to injecting leacheate into the soil, dissolving and analyzing the pollutants when it flows through the contaminated soil layer, and then processing and recycling the leacheate containing the pollutants. Commonly used leacheate are generally water, inorganic acids, inorganic salts, chelating agents and surfactants [15-16]. The injection of leacheate can change the adsorption and desorption characteristics of soil and pollutants, interfacial tension, dissolved precipitation state, Acidbase properties, etc., increasing the solubility of pollutants and making them in an emulsion or mobile state, which is convenient for removal from the soil [1718]. The column leaching or accumulation leaching in this method is more commonly used and is suitable for the restoration of a small area of heavily polluted soil, but it is easy to cause secondary pollution, resulting in the loss of soil nutrients, and may destroy the soil microaggregate structure and pollute groundwater[19-20].

Chemical reduction method refers to adding chemical reducing agents to heavy metal contaminated soil, such as iron filings, ferrous sulfate, calcium sulfate, etc., to restore pollutants to insoluble states, thereby reducing the pollutants migration in the soil and their biological effectiveness or use chemical reducing agents to change the valence of heavy metals and reduce their toxicity, such as the pollution restoration of $\mathrm{Cr}$ and $\mathrm{As}$ in the soil.

\subsection{Bioremediation technology}

Bioremediation technology refers to the use of plants, animals and microorganisms to absorb, degrade and transform pollutants in the soil to reduce the concentration of pollutants to the national standard limit. Bioremediation technology has the characteristics of low cost, less secondary pollution, and environmental protection.

Phytoremediation refers to the use of natural growth or genetically cultivated plants to absorb, degrade, volatilize, root filtration, stabilization, etc., to remove pollutants in the soil, or fix pollutants to reduce their 
harm. It can be divided into plant extraction, plant volatilization and plant stability.

Animal remediation is the use of generalized animals and their intestinal microbes under artificial control or natural conditions to metabolize, digest and enrich pollutants during life activities such as growth, reproduction, and metabolism in contaminated soil, so as to make pollutants reduce or eliminate.

Microbial remediation refers to the use of algae, bacteria, fungi and other microorganisms in the soil to absorb, deposit, oxidize or reduce certain heavy metals to reduce plant uptake, thereby reducing the toxicity of heavy metals [21].

\section{Conclusions and prospects}

In terms of contaminated soil remediation technology, Chinese scholars have conducted a lot of research on the remediation of heavy metal pollution in farmland soil in the past 10 years, explored and established some scientific and feasible technical models and remediation measures. However, due to the wide distribution of soils in agricultural production areas, huge differences in soil properties, and complex influencing factors as well as the fact that China's farmland pollution remediation needs to meet the national and agricultural conditions of production and remediation, different repair technologies still have various limitations and technical bottlenecks in the large-scale promotion and application.

In view of the characteristics and problems of various heavy metal contaminated soil remediation technologies, it is imperative to take measures based on the actual needs and goals of soil remediation and the latest developments in this field at home and abroad. There are a few recommendations. First, fully absorb various advanced technologies of heavy metal contaminated soils remediation at home and abroad, strengthen technology integration. Second, strengthen the research and development of environmentally friendly, low-cost and high-efficiency soil remediation technologies. Focus on electric remediation technology and chemical leaching remediation technology to prevent problems such as abnormal soil $\mathrm{pH}$, changes in soil physical and chemical properties, and secondary pollution. Finally, it is necessary to strengthen the development of new environmental remediation materials and select dominant species for bioremediation. Develop environmental functional materials with high-efficiency adsorption capacity, and develop degradable chelating agents with high chelating and complexing capabilities. At the same time, it is important to promote the combined utilization of herbs, woody plants, and microorganisms in the field of soil remediation projects.

\section{References}

1. H. M. Chen, Environmental Soil Science[M]. Beijing: Science Press, (2006).

2. F. L. Feng, J. M. Cheng, D. X. Wang, Soil Bulletin, 37(4), (2006).

3. J. Cheng, J. J. Gao, Research of Soil and Water Conservation, (6), (2006).

4. T. Fan, W. L. Ye , H. Y. Chen, et al. Journal of Ecological Environment, 22 (10), (2013).

5. Y. X. Chen , X. C. Chen, M. G. Yu, Environmental Pollution \& Control, 31 (12), (2009).

6. S. C. Yang, Anhui Agricultural Sciences, 34(3), (2006).

7. Q. X. Zhou, Y. F. Song, Beijing: Science Press, (2004).

8. M. Khalid, N. K. Shahid, B. Niazi, et al. Journal of Geochemical Exploration, 182 (2016).

9. Y. Y. Gong, D. Y. Zhao, Q. L. Wang, Water Research, 147 (2018).

10. B. G. Wei, L. S. Yang, Microchemical Journal, 94 (2010).

11. Z. W. Wang, Z. L. Wang, Heavy metal pollution and soil remediation in Tianjin sewage irrigation area[M]. Beijing: Science Press, (2014).

12. M. Cheng, G. Zeng, D. Huang, et al. Chemical Engineering Journal, 284 (2016).

13. D. S. Powlson, P. J. Gregory, W. R. Whalley, et al. Food Policy, 36 (2011).

14. A. M. Kunkel, J. J. Seibert, L. J. Elliott, et al. Environmental Science and Technology, 40(7), (2006).

15. L. Liu, S. P. Hu, Y. X. Chen, et al. Chinese Journal of Applied Ecology, 21(6), (2010).

16. I. W. KO, C. H. LEE, K. P. LEE, et al. Environmental Progress, 25 (1), (2006).

17. J. M. Zhou, Soil Science Dictionary [M]. Beijing: Science Press, (2013).

18. Y. S. Li, X. J. Hu, T. H. Sun, et al. Journal of Ecology, 30 (3), (2011).

19. X. H. MAO, R. JIANG, W. XIAO, et al. Journal of Hazardous Materials, 285(2015).

20. M. UDOVIC, D. LESTAN, Chemosphere, 74 (10) (2009).

21. Y. Teng, Y. M. Luo, Z. G. Li, Soil, 39 (4), (2007). 